\title{
Effect of Bench Time on Surface Hardness of Nanofiller Composite Resin
}

\author{
Kholidina Imanda Harahap*, Astrid Yudhit ${ }^{1}$, Febby Revita Sari \\ Department of Dental Material and Technology, Faculty of Dentistry Universitas Sumatera Utara, Medan, Indonesia \\ *Corresponding author: kholidinaimandaharahap@gmail.com
}

Received January 17, 2019; Revised February 20, 2019; Accepted February 26, 2019

\begin{abstract}
The purpose of this study was to evaluate the effect of different bench time on surface hardness of the composite resin after being stored in the refrigerator at $4^{\circ} \mathrm{C}$. Before used in this study, the composite resin was refrigerated at $4^{\circ} \mathrm{C}$ for the test group and kept at $25^{\circ} \mathrm{C}$ for the control group. The specimens were divided into control group (I) and five experimental groups according to the bench time before polymerization, 0 (II); 15 (III); 30 (IV); 45(V); and 60 (VI) minutes. Sixty specimens with $10 \mathrm{~mm}$ diameter and $2 \mathrm{~mm}$ thickness were made by using nanofiller composite resin. The material was filled into stainless steel mold and curing for $20 \mathrm{~s}$. After kept in a dark box for 24 hours, the surface hardness of all specimens were tested using Microhardness Tester. The data were analyzed with one-way ANOVA ( $\mathrm{p} \leq 0.05)$ and LSD's post hoct test. The results showed that the 60 minute bench time group presented the highest surface hardness value followed by 45, 30, 15 and 0 minutes bench time group. Moreover, the hardness value of 60 min group was almost similar with the control group. Statistical analysis showed no significant differences ( $\mathrm{p}>0.05$ ) between groups. It concluded, bench time has an effect on the surface hardness of composite resin but no significant differences statistically.
\end{abstract}

Keywords: bench time, hardness, nanofiler composite resin

Cite This Article: Kholidina Imanda Harahap, Astrid Yudhit, and Febby Revita Sari, "Effect of Bench Time on Surface Hardness of Nanofiller Composite Resin.” International Journal of Dental Sciences and Research, vol. 7, no. 1 (2019): 18-20. doi: 10.12691/ijdsr-7-1-4.

\section{Introduction}

Composite resin is the most widely used restorative material in dentistry. The advantages of composite resins in mimicking the original tooth color is the reason of its frequently used. The success of composite resin restoration obtained from its aesthetic value and durability of use over a long period of time.

Some of the parameters that may affect the polymerization of composite resins are composition, color and translucency, light curing unit characteristics, irradiation distance, exposure time and temperature. Temperature may affect the polymerization of the composite resin, which affects the properties of the composite resin and its quality. An adequate polymerization of composite resin will increase the degree of conversion that influence the properties of composite resin, such as strength, hardness, water sorption and solubility [1].

Hardness is one of mechanical properties of composite resins which indicates the ability of a material to resist plastic deformation such as abration, scratching, etc. Several studies have shown a relationship between degree of conversion and hardness of composite resins. Surface hardness test can be used as an alternative method to evaluate the degree of conversion. As the number of monomers transformed into polymers increases, the degree of conversion also increases, resulting in increased its surface hardness [2].

Manufacturers recommended to keep the composite resin in refrigerator for extend its shelf life. Meanwhile these recommendation was not followed by proper instructions about the time to use it after taken out from refrigerator. The dentists usually use it immediately after taken out from refrigerator.

A few studies have reported about effect of refrigeration on the properties of composite resin such as hardness, viscosity and depth of cure. Composite resin that used immediately after removal from $4^{\circ} \mathrm{C}$ has higher viscosity and lower degree of conversion and hardness [3,4]. Other study found that composite resins after being stored at $5^{\circ} \mathrm{C}$ have a lower microhardness than stored at $24^{\circ} \mathrm{C}$ and $54^{\circ} \mathrm{C}$ [5].

Temperature had effect on the polymerization reaction of composite resin. High temperature can decreased the viscosity of composite resin, due to can accelerate the mobility of monomer molecules within the resin matrix of composite resin [6]. To increase the temperature of the composite resin before polymerization can heat it by using a warmer device or allow for a while at room temperature [5]. Time to let the composite resin reach its optimum temperature without warmer device called bench time.

The aim of this study was to evaluate the effect of different bench time on hardness of composite resin after storage in refrigerator. The null hypothesis was there are 
no significant effect of bench time on the hardness of composite resin.

\section{Materials and Methods}

This research is experimental laboratory with post only control group design. Sixty samples in this study were made from nanofiller composite resin (Filtek Z 350, 3M ESPE, USA). Samples were divided into 6 groups that are control, test groups with different bench time 0, 15, 30, 45 and 60 minutes after taken out from refrigerator. For control group, materials was stored in room temperature $\left(25^{\circ} \mathrm{C}\right)$ for two weeks. For test groups, materials was stored in the refrigerator at $4^{\circ} \mathrm{C}$ for two weeks.

\subsection{Sample Preparations}

For making samples of experimental groups, composite resin was placed in room temperature after removed from the refrigerator according the bench time respectively. The material is filled into a mold with a diameter of $6 \mathrm{~mm}$ and a thickness of $2 \mathrm{~mm}$. The mold has been smeared with silicon oil and with celluloid strips and glass slide on its base. Composite resins that were filled into the mold were covered with celluloid strips and were pressed using glass slides. Then the mold is moved onto filter paper and the material is cured for 20 seconds using light curing unit (Litex 680A, Dentamerica, China). Samples were removed from the mold and trimmed, then stored in a dark container for 24 hours.

\subsection{Microhardness Test}

Surface hardness of samples was tested using microhardness tester (Microhardness tester FM-800, Future Tech Crop, Japan). Indentations are made on the top surface at three different points with a load of 200 grams for 15 seconds respectively. The microhardness value is obtained from the indentation diameter measurement.

\subsection{Statistical Analysis}

The results were analyzed using one way ANOVA test and differences among the groups were assessed using the Least Significant Data post-hoc test. P-values less than 0.05 were considered statistically significant.

\section{Results}

Table 1 show the mean and standard deviation of hardness value of samples in all groups. The highest hardness among the experimental groups is group with 60 minutes bench time $(68.62 \pm 10.69 \mathrm{VHN})$ and the lowest hardness is group with 0 minutes bench time $(60.1 \pm 17.10$ $\mathrm{VHN})$. The mean hardness in control group are $69.41 \pm 17.84 \mathrm{VHN}$. The hardness value in group with 60 minutes bench time almost equal with control group.

Analysis of one-way ANOVA followed by LSD test showed no significant difference statistically between the control group and all the experimental groups $(\mathrm{p}=0.64)$.
Table 1. Mean and standard deviation of surface hardness value (VHN) for different of bench time

\begin{tabular}{|c|c|c|}
\hline Groups & Mean \pm Standard Deviation & $\mathrm{p}$ \\
\hline Control & $69.41 \pm 17.84$ & \multirow{2}{*}{$0.64^{\mathrm{a}}$} \\
\hline $0^{\prime}$ ' bench time & $60.10 \pm 17.10$ & \\
\hline 15' bench time & $63.21 \pm 14.09$ & \\
\hline 30' bench time & $65.24 \pm 7.58$ & \\
\hline 45' bench time & $65.24 \pm 7.51$ & \\
\hline 60 ' bench time & $68.62 \pm 10.69$ & \\
\hline
\end{tabular}

No significant differences (Anova $(\mathrm{p}<0.05)$.

\section{Discussion}

Temperature plays an important role in polymerization because it related to the viscosity of composite resins. High temperatures will decrease the viscosity of the composite resin. Viscosity was correlated to the speed of monomer molecules movement during polymerization. Raising the temperature before polymerization will increase the degree of conversion for producing a better polymer network. In high temperature, the mobility of monomer molecules will be faster and propagation stage will be longer to induce a large amounts the monomer conversion [7,8]. Meanwhile a low temperatures can increase the viscosity of the composite resin which will slows the movement of monomer molecules to polymerize. Because decreasing the speed of monomers movement can causes the propagation and termination phases to end faster. In the low temperature, only some of the monomers converted into a polymer with low degree of conversion [4].

An adequate polymerization will produce a composite resin with a higher of cross-linking network and have better mechanical properties. Hardness is an important mechanical property of composite resins as a restorative material. Hardness indicates the ability of a material to withstand the abrasion force of a structure to which it is attached. The hardness value of the composite resin indirectly illustrates the degree of polymerization formed [9].

Previous studies have reported the effect of temperature on hardness of composite resin. Composite resins after being stored at $5^{\circ} \mathrm{C}$ and $24^{\circ} \mathrm{C}$ must be preheated to improve the hardness [5]. Pre-heated composite resins before polymerization will increase the degree of conversion and hardness [10,11].

In this study, composite resin with bench time 60 minutes has the highest hardness compared to composite resin with bench time $0,15,30$ and 45 minutes. Hardness of group with 60 minute bench time were also almost equal to control group. This is likely due to temperature of composite resin after 60 minutes taken out from refrigerator almost same as the temperature of the composite resin stored at room temperature. While the composite resin that is directly polymerized (bench time 0 min) after being removed from the refrigerator has the lowest hardness value. However, there is no significant differences in hardness between different bench time.

Visually, the consistency of composite resins stored in refrigerators is more rigid and more difficult to be 
manipulated than stored at room. By allowing the composite resin at room temperature for a certain time after removal from the refrigerator there will be temperature adjustment. This will decrease the viscosity of composite resin so that its consistency is softer and easier to manipulate the material.

According to the previous study, resin-based adhesives should be removed from the refrigerator for at least 20 minutes before use in order to obtain optimal viscosity for polymerization [4]. Preheating of the composite resin will decrease its viscosity and will increase the surface hardness. This will facilitate the placement of materials and increase the degree of polymerization and depth of cure [12]. Other study found that lied composite resin for a while at room temperature after being removed from the refrigerator will increase the depth of cure. Composite resins with bench time 60 minutes after being stored in the refrigerator has a higher hardness compared to composite resins that are directly used after removal from the refrigerator [13]. Pre-heated composite resin before cured has the higher depth of cure [14].

\section{Conclusions and Recommendations}

Based on the results and with limitations during the study, it can be concluded that the bench time has an effect on the surface hardness of composite resin. The longer bench time will increase the surface hardness of composite resin. However, there is no significant differences in surface hardness of composite resin with different bench time. For the next study, it is better to examine composite resin temperature to get more accurate results. For clinical advise, it is recommendation to allow the composite resin at room temperature for 60 minutes after removal from refrigeration before its used for filling.

\section{Acknowledgements}

We would like to thank Universitas Sumatera Utara for funding this research by awarding the Talenta Grant 2016.

\section{Conflict of Interest}

No potential conflict of interest was reported related to this article.

\section{References}

[1] M. M. Al Shaafi, The Saudi Dental Journal, 29, 48, (2017).

[2] K. J. Anusavice, Philip's Science of Dental Materials, 12th ed, Elsevier, St.Louis (2013).

[3] F. H.R. Osternack, D. B.M. Caldas, N. R. Rached, S. Vieira, A. J. Platt, and J. B. de Almeida, Braz. Dent J, 20, 42, (2009).

[4] A. L. Faria-e-Silva, E. Piva, and R. R. Moraes, European Journal of Dentistry, 4, 150, (2010).

[5] C. R. G. Torres, F. M. T. Caneppele,B. A. Borges, A. C. M. Torres, and M. A. M. Araújo, IJCD, 2, 41, (2011).

[6] W. M. Palin, M.A. Hadis, JG Leprince, G. ILeloup, L. Boland, GJ Fleming, G. Krastl. DC Watts, Dent. Mater, 30, 507, (2014).

[7] M. Daronch, F. A. Rueggeberg, M. F. De Goes, and R. Giudici, J Dent Res, 85, 38, (2006).

[8] M. Daronch, F. A. Rueggeberg, and M. F. De Goes, J Dent Res, 84, p. 663, (2005).

[9] N. Prasanna, Y. Pallavi Reddy, S. Kavitha, and L. Lakshmi Narayanan, Indian J Dent Res, 8, 173, (2014).

[10] W. Awliya, J.Contemp Dent Pract, 8, 9, (2007).

[11] T. S. J. Kashi, F. Fereidouni, K. Khoshroo, S. Heidari, R. Masaeli, and M. Mohammadian, Biomedical Technologies, 2, 15, (2015).

[12] S. Lucey, C. D. Lynch, N. J. Ray, F. M. Burke, and A. Hannigan, Journal of Oral Rehabilitation, 1, (2009).

[13] K. Harahap, A. Yudhit, and F. Sari. Effect of bench time polymerization on depth of cure of dental composite resin. IOP Conf. Ser.: Mater. Sci. Eng. 223 012062, 1, (2017).

[14] C. A. Munoz, P.R. Bond, J. S. Y. Munoz, D. Tan, and J. Peterson, American Journal of Dentistry, 21, 215, (2008). 